NASA/TM-2004-212985

ARL-TR-3178
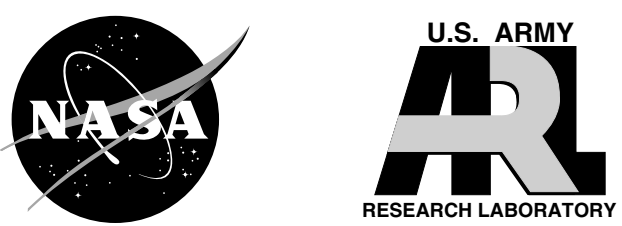

\title{
Strain-Life Assessment of Grainex Mar-M 247 for NASA's Turbine Seal Test Facility
}

Irebert R. Delgado

U.S. Army Research Laboratory, Glenn Research Center, Cleveland, Ohio

Gary R. Halford and Bruce M. Steinetz

Glenn Research Center, Cleveland, Ohio

Clare M. Rimnac

Case Western Reserve University, Cleveland, Ohio 
Since its founding, NASA has been dedicated to the advancement of aeronautics and space science. The NASA Scientific and Technical Information (STI) Program Office plays a key part in helping NASA maintain this important role.

The NASA STI Program Office is operated by Langley Research Center, the Lead Center for NASA's scientific and technical information. The NASA STI Program Office provides access to the NASA STI Database, the largest collection of aeronautical and space science STI in the world. The Program Office is also NASA's institutional mechanism for disseminating the results of its research and development activities. These results are published by NASA in the NASA STI Report Series, which includes the following report types:

- $\quad$ TECHNICAL PUBLICATION. Reports of completed research or a major significant phase of research that present the results of NASA programs and include extensive data or theoretical analysis. Includes compilations of significant scientific and technical data and information deemed to be of continuing reference value. NASA's counterpart of peerreviewed formal professional papers but has less stringent limitations on manuscript length and extent of graphic presentations.

- TECHNICAL MEMORANDUM. Scientific and technical findings that are preliminary or of specialized interest, e.g., quick release reports, working papers, and bibliographies that contain minimal annotation. Does not contain extensive analysis.

- CONTRACTOR REPORT. Scientific and technical findings by NASA-sponsored contractors and grantees.
- CONFERENCE PUBLICATION. Collected papers from scientific and technical conferences, symposia, seminars, or other meetings sponsored or cosponsored by NASA.

- SPECIAL PUBLICATION. Scientific, technical, or historical information from NASA programs, projects, and missions, often concerned with subjects having substantial public interest.

- TECHNICAL TRANSLATION. Englishlanguage translations of foreign scientific and technical material pertinent to NASA's mission.

Specialized services that complement the STI Program Office's diverse offerings include creating custom thesauri, building customized databases, organizing and publishing research results ... even providing videos.

For more information about the NASA STI Program Office, see the following:

- Access the NASA STI Program Home Page at http://www.sti.nasa.gov

- E-mail your question via the Internet to help@sti.nasa.gov

- Fax your question to the NASA Access Help Desk at 301-621-0134

- Telephone the NASA Access Help Desk at 301-621-0390

- Write to:

NASA Access Help Desk

NASA Center for AeroSpace Information 7121 Standard Drive

Hanover, MD 21076 
NASA/TM-2004-212985

ARL-TR-3178
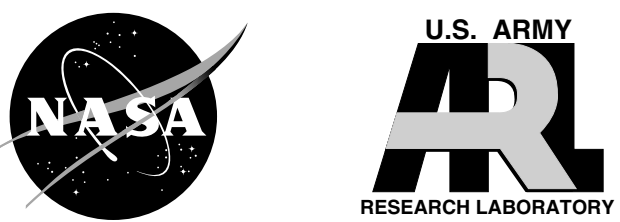

\section{Strain-Life Assessment of Grainex Mar-M 247 for NASA's Turbine Seal Test Facility}

Irebert R. Delgado

U.S. Army Research Laboratory, Glenn Research Center, Cleveland, Ohio

Gary R. Halford and Bruce M. Steinetz

Glenn Research Center, Cleveland, Ohio

Clare M. Rimnac

Case Western Reserve University, Cleveland, Ohio

Prepared for the

Turbo Expo 2004

sponsored by the American Society of Mechanical Engineers

Vienna, Austria, June 14-17, 2004

National Aeronautics and

Space Administration

Glenn Research Center 


\section{Acknowledgments}

The authors wish to acknowledge NASA Glenn Research Center, the Army Research Laboratory, and Case Western Reserve University for their support.

This report is a formal draft or working paper, intended to solicit comments and ideas from a technical peer group.

Trade names or manufacturers' names are used in this report for identification only. This usage does not constitute an official endorsement, either expressed or implied, by the National Aeronautics and Space Administration.

Available from

NASA Center for Aerospace Information 7121 Standard Drive

Hanover, MD 21076
National Technical Information Service 5285 Port Royal Road Springfield, VA 22100 


\title{
STRAIN-LIFE ASSESSMENT OF GRAINEX MAR-M 247 FOR NASA'S TURBINE SEAL TEST FACILITY
}

\author{
Irebert R. Delgado \\ U.S. Army Research Laboratory \\ Glenn Research Center \\ Cleveland, Ohio 44135 \\ Gary R. Halford and Bruce M. Steinetz \\ National Aeronautics and Space Administration \\ Glenn Research Center \\ Cleveland, Ohio 44135 \\ Clare M. Rimnac \\ Case Western Reserve University \\ Cleveland, Ohio 44106
}

\begin{abstract}
NASA's Turbine Seal Test Facility is used to test air-toair seals for use primarily in advanced jet engine applications. Combinations of high temperature, high speed, and high pressure limit the disk life, due to the concern of crack initiation in the bolt holes of the Grainex Mar-M 247 disk. The primary purpose of this current work is to determine an inspection interval to ensure safe operation. The current work presents high temperature fatigue strainlife data for test specimens cut from an actual Grainex MarM 247 disk. Several different strain-life models were compared to the experimental data including the MansonHirschberg Method of Universal Slopes, the HalfordNachtigall Mean Stress Method, and the Modified Morrow Method. The Halford-Nachtigall Method resulted in only an $18 \%$ difference between predicted and experimental results. Using the experimental data at a $-99.95 \%$ prediction level and the presence of 6 bolt holes it was found that the disk should be inspected after 665 cycles based on a total strain of $0.5 \%$ at $649{ }^{\circ} \mathrm{C}$.
\end{abstract}

\section{INTRODUCTION}

The High Temperature High Speed Turbine Seal test facility (figure 1), located at NASA's Glenn Research Center in Cleveland, Ohio provides critical testing of air seals for aircraft engines at conditions of high air temperatures, high seal pressures, and surface speeds greater than $305 \mathrm{~m} / \mathrm{s}$.

The test facility uses a disk made of Grainex Mar-M 247, a cast nickel based superalloy. Analysis has shown that, in the vicinity of the disk bolt holes, the material slightly enters the plastic region of the stress-strain curve [1]. Due to these demanding test conditions, the possibility exists that fatigue cracks will develop with cycling at the 6 bolt hole locations, which fasten the test disk to the main shaft of the test stand. If allowed to grow to a critical size, the cracks could cause the disk to catastrophically burst during use.

Preliminary analyses by Tong and Steinetz [1] have placed a strain-life fatigue limit, $L_{s y s}$, of 6000 cycles based upon an equivalent $-3 \sigma$ reduction factor and a probabilistic approach [2] accounting for $n=6$ bolt holes:

$$
L_{s y s}=\frac{L}{n^{\frac{1}{e}}}
$$

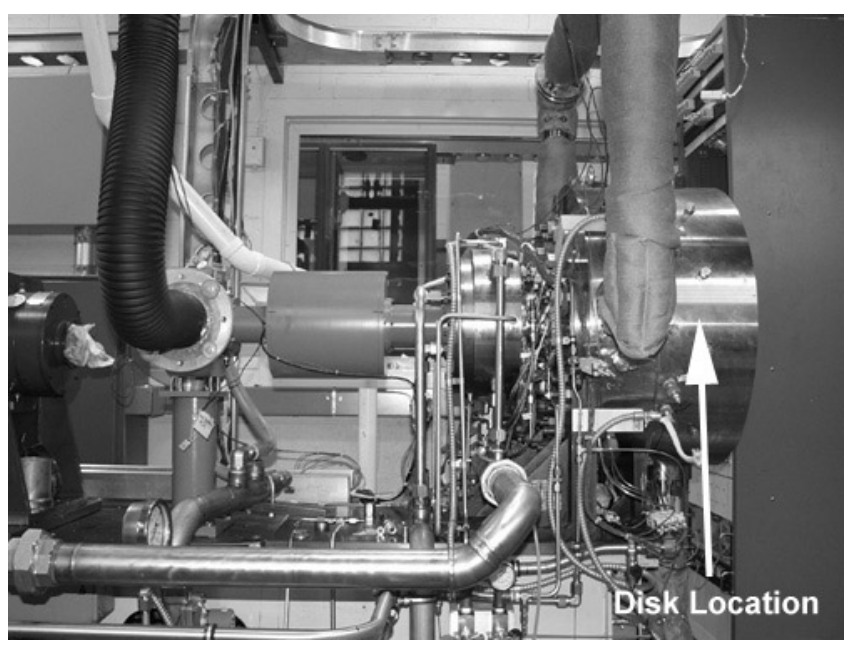

Figure 1.-NASA Glenn Research Center turbine seal test facility. 
eq. (1) is based on the Lundberg-Palmgren [3] analysis for rolling element bearing system lives. $L$ is the predicted life for a disk with a single bolt hole. The predicted life, $L$, and Weibull slope parameter, $e$, are assumed to be identical for all six disk bolt holes. One cycle is defined as a ramp up and down in speed.

In this study, strain-life tests were conducted over various strain ranges at a temperature of $649^{\circ} \mathrm{C}$ to determine the cycles to crack initiation. This data was compared with previous analyses as well as literature data and strain-life model estimates based upon tensile data.

\section{NOMENCLATURE}

\begin{tabular}{|c|c|c|}
\hline $3 \sigma$ & $=$ & 3 standard deviations \\
\hline$A$ & $=$ & constant coefficient \\
\hline$B$ & $=$ & constant coefficient \\
\hline$C$ & $=$ & constant coefficient \\
\hline$b$ & $=$ & fatigue strength exponent \\
\hline$c$ & $=$ & fatigue ductility exponent \\
\hline$e$ & $=$ & Weibull slope parameter $=3.57$ (Gaussian) \\
\hline$E$ & $=$ & Young's Modulus \\
\hline$k$ & $=$ & transfer function \\
\hline$L$ & $=$ & calculated disk life \\
\hline$L_{\text {sys }}$ & $=$ & overall system life \\
\hline$n$ & $=$ & number of bolt holes $=6$ \\
\hline$R$ & $=$ & strain ratio $=\varepsilon_{\min } / \varepsilon_{\max }$ \\
\hline$R^{2}$ & $=$ & coefficient of determination \\
\hline$N_{i}$ & $=$ & cycles to crack initiation \\
\hline$N_{f}$ & $=$ & cycles to failure \\
\hline$N_{t 0}$ & $=$ & transition life under zero mean stress \\
\hline$N_{f 0}$ & $=$ & cycles to failure under zero mean stress \\
\hline$N_{f m}$ & $=$ & cycles to failure in presence of mean stress \\
\hline$V_{e f f}$ & $=$ & $\begin{array}{l}\text { effective ratio of mean stress to stress } \\
\text { amplitude }\end{array}$ \\
\hline$V_{\sigma}$ & $=$ & ratio of mean stress to stress amplitude \\
\hline$\alpha$ & $=$ & constant exponent \\
\hline$\delta \sigma_{m}$ & $=$ & change in mean stress $[\mathrm{MPa}]$ \\
\hline$\Delta \varepsilon$ & $=$ & total strain range \\
\hline$\Delta \varepsilon_{e l}$ & $=$ & elastic strain range \\
\hline$\Delta \varepsilon_{i n}$ & $=$ & inelastic strain range \\
\hline$\Delta \sigma$ & $=$ & stress range $[\mathrm{MPa}]$ \\
\hline$\varepsilon_{a}$ & $=$ & strain amplitude \\
\hline$\varepsilon_{f}$ & $=$ & true fracture ductility \\
\hline$\varepsilon_{f}^{\prime}$ & $=$ & fatigue ductility coefficient \\
\hline$\varepsilon_{f}$ & $=$ & true fracture strain \\
\hline$\varepsilon_{\min }$ & $=$ & minimum strain \\
\hline$\varepsilon_{\max }$ & $=$ & maximum strain \\
\hline$\sigma_{a}$ & $=$ & stress amplitude [MPa] \\
\hline$\sigma_{f}^{\prime}$ & $=$ & fatigue strength coefficient $[\mathrm{MPa}]$ \\
\hline$\sigma_{f}$ & $=$ & true fracture strength $[\mathrm{MPa}]$ \\
\hline$\sigma_{m}$ & $=$ & mean stress $[\mathrm{MPa}]$ \\
\hline$\sigma_{u t s}$ & $=$ & ultimate tensile strength $[\mathrm{MPa}]$ \\
\hline$\sigma_{y 0.2 \%}$ & $=$ & $0.2 \%$ yield strength $[\mathrm{MPa}]$ \\
\hline$\% E L$ & $=$ & percent elongation \\
\hline$\% R A$ & $=$ & percent reduction in area \\
\hline$\% \Delta \varepsilon$ & $=$ & percent total strain range \\
\hline
\end{tabular}

MATERIALS AND METHODS: TENSILE BEHAVIOR

\section{Experimental}

Tensile tests were performed at Mar-Test Inc. in Cincinnati, Ohio per ASTM E-8, ASTM E-21, and ASTM E83 Class B-2 standards. The tensile test specimen geometry was $3.56 \mathrm{~mm}$ in diameter by $50.8 \mathrm{~mm}$ in length per ASTM E-8 small-size specimens. Four tensile specimens were taken from a Grainex Mar-M 247 sacrificial disk and tested. Tensile testing was conducted on a hydraulic servo controlled test system with a box furnace for specimen heating. Thermocouples were positioned at the gage radius to monitor temperature. The tensile tests were conducted at $649{ }^{\circ} \mathrm{C}$ at a strain-rate of $0.00028 \mathrm{~s}^{-1}$.

\section{MATERIALS AND METHODS: FATIGUE STRAIN- LIFE BEHAVIOR}

\section{Experimental}

Fatigue strain-life testing was also performed at MarTest, using a closed loop, servo-hydraulic test system complying with ASTM E-4, ASTM E-606, and ASTM E-83 Class B-2 standards. Induction heating was utilized for specimen heating. Test temperature was controlled to within $1 \%$.

The specimen geometry was $3.18 \mathrm{~mm}$ in diameter and $50.8 \mathrm{~mm}$ in length per ASTM E-606 standards. A total of 15 strain-life specimens were obtained from the sacrificial disk. The tests were conducted in air at $649{ }^{\circ} \mathrm{C}$ at a strain ratio of $R=0$, cycled at $0.33 \mathrm{~Hz}$ using a triangular waveform. Five strain ranges were tested $(0.50 \%, 0.58 \%, 0.67 \%, 0.78 \%$, and $0.90 \%$ ) with three repeats at each strain range. The cycles to crack initiation, $N_{i}$, and cycles to failure, $N_{f}$, were recorded for each test. $N_{i}$ was defined as a rapid change in the load versus time history plot (figure 2) while $N_{f}$ was defined as complete specimen separation.

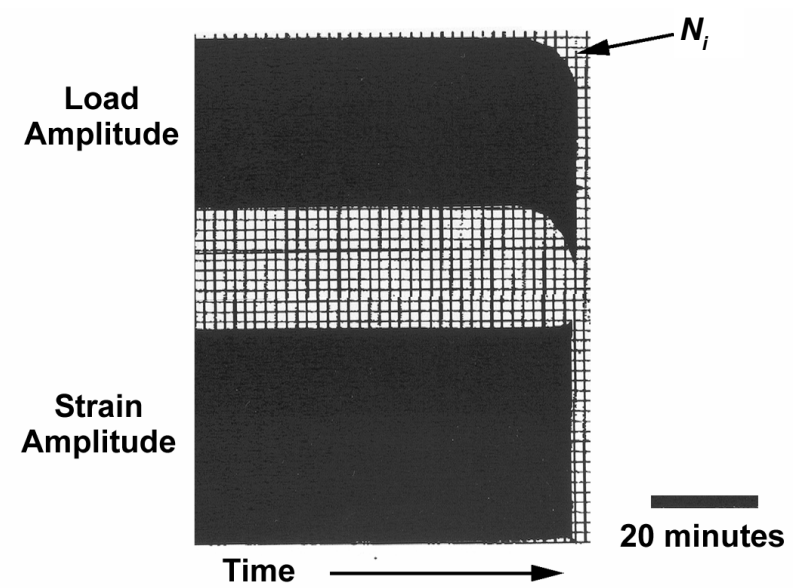

Figure 2.-Sample load- and strain-time history indicating $N_{i}$. 


\section{Data Analysis}

The fatigue strain-life results were evaluated following a simple linear model in log-log coordinates:

$$
N_{f}=A(\% \Delta \varepsilon)^{\alpha}
$$

where the constant $A$ and exponent $\alpha$ were determined. Linear regression analysis of the log-log transformed fatigue strain-life behavior was conducted to determine the coefficient $A$ and the exponent $\alpha$ for the $R=0$ data. Thus,

$$
\log \left(N_{f}\right)=\log A+\alpha \log (\% \Delta \varepsilon)
$$

Standard statistical analyses were also performed to check for significance of the regression, $R^{2}$, test for normal distribution, outliers, lack-of-fit, and also to calculate the $-99.95 \%$ prediction interval. [4]

\section{Method of Universal Slopes}

The Manson-Hirschberg Method of Universal Slopes (MUS) was used to estimate strain life with zero mean stress based only upon tensile data [5]:

$$
\begin{gathered}
\Delta \varepsilon=\Delta \varepsilon_{e l}+\Delta \varepsilon_{p l} \\
\Delta \varepsilon=B N_{f}^{b}+C N_{f}^{c} \\
\Delta \varepsilon=3.5 \frac{\sigma_{u t s}}{E}\left(N_{f 0}\right)^{-0.12}+\varepsilon_{f}^{0.6}\left(N_{f 0}\right)^{-0.6}
\end{gathered}
$$

Thus, the total strain range is the sum of the elastic strain range (first term) and the plastic strain range (second term).

\section{Mean Stress Effects}

To estimate the effect of mean stress on cyclic life the Halford-Nachtigall Method was used with the MUS [6]:

$$
N_{f m}^{-b}=N_{f 0}^{-b}-V_{\sigma}
$$

The relationship is derived from [7]:

$$
\Delta \sigma=2\left(\sigma_{f}^{\prime}-\sigma_{m}\right) N_{f m}^{-b}
$$

This is Morrow's original equation [8] except that $N_{f m}$ is used instead of $2 N_{f m}$.

The value for $b$ was -0.12 from the MUS. $N_{f 0}$ was calculated using the ratio of the inelastic strain range and the elastic strain range from the MUS at ratios of $0.3,0.2,0.1$, $0.08,0.05$, and 0.02 . $V_{\text {eff }}$ was substituted for $V_{\sigma}[6]$ :

where

$$
V_{\text {eff }}=k \frac{\sigma_{m}}{\sigma_{a}}=k V_{\sigma}
$$

and

$$
k=\exp \left[-70\left(\frac{\Delta \varepsilon_{i n}}{\Delta \varepsilon_{e l}}\right)^{2}\right]
$$

At the beginning of each test, note that for zero to maximum loading it is assumed that $\frac{\sigma_{m}}{\sigma_{a}}=1$. This could be true if the cycle is elastic, but as plasticity is encountered the mean stress ratio begins to relax according to eq. (9) and eq. (10).

\section{Modified Morrow with Mean Stress Effects}

The Modified Morrow equation was used to account for mean stress, $\sigma_{m}$, effects resulting from the $R=0$ tests [7]:

$$
\varepsilon_{a}=\frac{\sigma_{f}^{\prime}}{E}\left(1-\frac{\sigma_{m}}{\sigma_{f}^{\prime}}\right)\left(2 N_{f}\right)^{b}+\varepsilon_{f}^{\prime}\left(1-\frac{\sigma_{m}}{\sigma_{f}^{\prime}}\right)^{\frac{c}{b}}\left(2 N_{f}\right)^{c}
$$

The coefficients and exponents were calculated using the $R=0$ strain-life test data and $E$ from the tensile tests. Constraints were placed on exponents $b$ and $c$ based upon previous observations on engineering metal behavior [7]:

$$
-0.12 \leq b \leq-0.05
$$

and

$$
-0.9 \leq c \leq-0.5
$$

In using eq. (11), various values of $\sigma_{m}$ were assumed as needed.

\section{Fractographic Examination}

The fracture surfaces of fatigued specimens were cleaned in acetone, alcohol rinsed, and air dried to facilitate fractographic examination. Surfaces were examined using light stereomicroscopy and a JEOL JSM-840A scanning electron microscope (SEM) using secondary electron [SE] and backscattered electron $[\mathrm{BE}]$ modes to determine crack initiation sites.

\section{RESULTS: TENSILE BEHAVIOR}

\section{Properties}

Mean tensile properties of the four tensile tests for the Grainex Mar-M 247 material were determined at $649^{\circ} \mathrm{C}$ and are shown in table 1 . The ultimate tensile strength and $0.2 \%$ offset yield stress were found to be $1064 \mathrm{MPa}$ and $821 \mathrm{MPa}$, respectively.

Table 1.-Mean tensile test results for Grainex Mar-M 247 at $649{ }^{\circ} \mathrm{C}$.

\begin{tabular}{|c|c|c|c|c|c|c|c|}
\hline & $\begin{array}{c}E \\
\mathrm{GPa}\end{array}$ & $\begin{array}{c}\sigma_{u t s} \\
\mathrm{MPa}\end{array}$ & $\begin{array}{c}\sigma_{y 0.2 \%} \\
\mathrm{MPa}\end{array}$ & $\% R A$ & $\% E L$ & $\begin{array}{c}\sigma_{f} \\
\mathrm{MPa}\end{array}$ & $\varepsilon_{f}$ \\
\hline avg & 194.3 & 1064 & 821.0 & 16 & 6.9 & 1268 & 0.177 \\
\hline $\begin{array}{c}\text { std. } \\
\text { dev. }\end{array}$ & 12.6 & 20 & 18.3 & 1 & 1.0 & 31 & 0.015 \\
\hline
\end{tabular}




\section{RESULTS: FATIGUE STRAIN-LIFE}

$\boldsymbol{R}=\mathbf{0}$

The cycles to crack initiation, $N_{i}$, and cycles to failure, $N_{f}$, were determined for each of the $R=0$ fatigue strain-life tests at $649{ }^{\circ} \mathrm{C}$ (table 2). Due to cycle recorder malfunctions in the data acquisition system, some results were unavailable.

Linear regression analysis of the $R=0$ total strain range versus cycles to crack initiation $\left(N_{i}\right)$ cyclic strain life tests (table 2) resulted in an exponent, $\alpha$, of -6.48 and a coefficient, $A$ of 162.18 with $R^{2}=0.86$ using eq. (2). (figure $3,99.95 \%$ prediction interval shown).

Linear regression analysis of the $R=0$ total strain range versus cycles to failure $\left(N_{f}\right)$ cyclic strain life tests (table 2) resulted in an exponent, $\alpha$, of -5.62 and a coefficient, $A$, of 316.23 with $R^{2}=0.87$ using eq. (2). (figure $4,99.95 \%$ prediction interval shown).

Table 3 summarizes the mean and $-99.95 \%$ prediction cyclic life for the $R=0$ data at both cycles to crack initiation and cycles to failure at the $0.5 \%$ design strain range of the Grainex Mar-M 247 disk (see also figures 3 and 4). The $-99.95 \%$ prediction intervals give a failure rate of 1 in 2000 parts.

Table 2.-Grainex Mar-M 247 strain-life test results at $649^{\circ} \mathrm{C}, \boldsymbol{R}=0$.

\begin{tabular}{|c|c|c|}
\hline$\% \Delta \varepsilon$ & $N_{i}$ & $N_{f}$ \\
\hline 0.50 & 25917 & 26939 \\
\hline 0.50 & 9557 & 10697 \\
\hline 0.58 & 12266 & 12566 \\
\hline 0.58 & 2450 & 2842 \\
\hline 0.58 & 5910 & 7970 \\
\hline 0.67 & 2056 & 3056 \\
\hline 0.67 & 3114 & 3842 \\
\hline 0.67 & 1322 & 2234 \\
\hline 0.78 & 585 & 723 \\
\hline 0.78 & 792 & 1352 \\
\hline 0.78 & 680 & 1254 \\
\hline 0.90 & 513 & 889 \\
\hline 0.90 & $*$ & 554 \\
\hline$* N_{i}$ occurred between 295 and 500 cycles. \\
\hline
\end{tabular}

Table 3.-Grainex Mar-M 247 mean and -99.95\% cyclic strain-life predictions at $649^{\circ} \mathrm{C}$ at the $0.5 \%$ design strain range.

\begin{tabular}{|c|c|c|}
\hline R-Level & \multicolumn{2}{|c|}{0} \\
\hline Statistic & Mean & $-99.95 \%$ \\
\hline$N_{i}$ (cycles) & 14500 & 1100 \\
\hline$N_{f}$ (cycles) & 15500 & 1600 \\
\hline
\end{tabular}

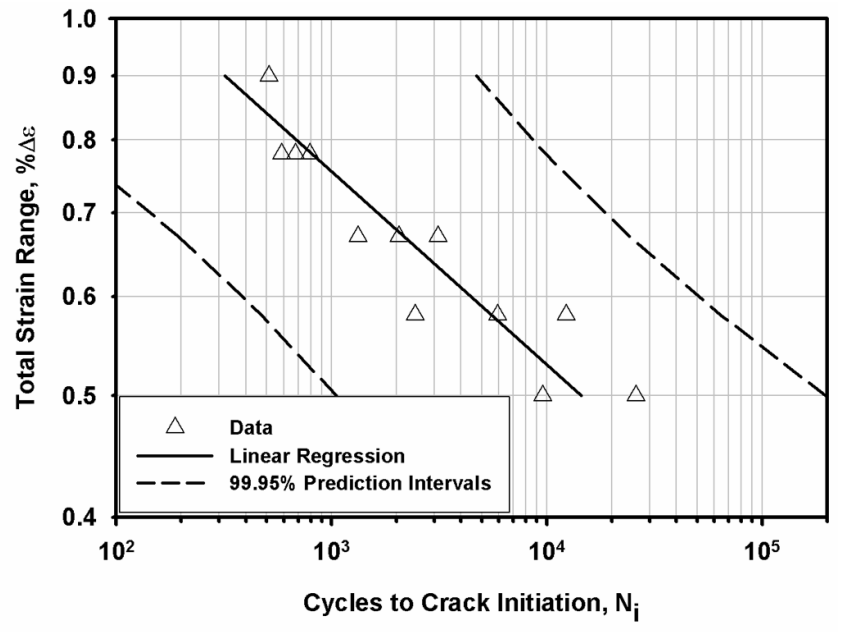

Figure 3.-Crack initiation strain-life results for Grainex Mar-M 247, $R=0,649^{\circ} \mathrm{C}$, triangular waveform, $0.33 \mathrm{~Hz}$. $N_{i}$ was plotted on the abscissa while $\% \Delta \varepsilon$ was plotted on the ordinate.

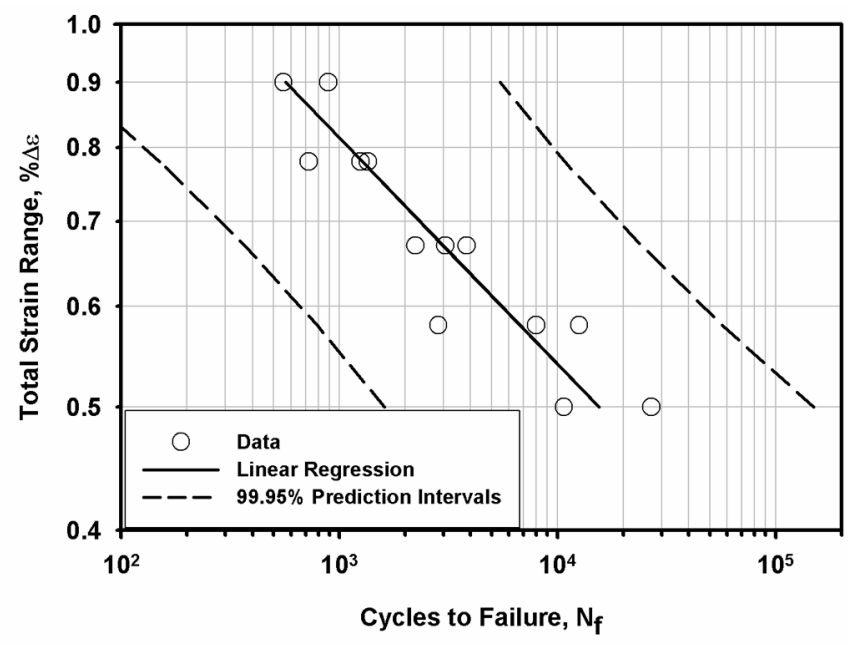

Figure 4.-Cycles to failure strain-life results for Grainex Mar-M 247, $R=0,649^{\circ} \mathrm{C}$, triangular waveform, $0.33 \mathrm{~Hz}$. $N_{f}$ is plotted on the abscissa while $\% \Delta \varepsilon$ is plotted on the ordinate.

\section{Method of Universal Slopes}

The estimated cycles to failure, $N_{f 0}$, was plotted against the total strain range, $\Delta \varepsilon$, for the Grainex Mar-M 247 material using tensile data (table 1) as input for the MUS (figure 5). The plastic and elastic strain lines were also plotted. The transition life, $N_{t 0}$, wherein the elastic and plastic strain ranges are equal, was found to be 400 cycles to failure. 


\section{Mean Stress Effect}

A comparison was made between the MUS, the MUS with mean stress effects (eq. (7)), and $R=0$ data for the Grainex Mar-M 247 material (figure 6). The $0.5 \%$ design strain is also shown in figure 6 and compared with the data and both estimation methods.

\section{Modified Morrow with Mean Stress Effects}

Calculated coefficients and exponents for the Modified Morrow equation, eq. (11), resulted in an $R^{2}$ value of 0.93 . The coefficients and exponents (table 4) were then used in the Modified Morrow equation and compared to experimental Grainex Mar-M 247 strain-amplitude data (figure 7). The design strain of the Grainex Mar-M 247 disk is also shown at $0.5 \%$ strain range.

Assuming the ratio of mean to alternating stress was equal to 1 at the start of the strain-life tests, $V_{\sigma}$ was calculated at the approximate half-life for each test (table 5).

The variation of mean stress and range of stress was also compared with increasing strain amplitude (figure 8). Point P1 through point P2 is the elastic line. Point P2 defines where the mean stress and range of stress are equal. Point P3 defines the point of zero mean stress. Finally, point P3 to P4 is the region of zero mean stress.

Table 4.-Calculated coefficient and exponent values for the Modified Morrow Equation for Grainex Mar-M 247 at $649^{\circ} \mathrm{C}$.

\begin{tabular}{|c|c|}
\hline Coefficients & Value \\
\hline$\sigma_{f}^{\prime}(\mathrm{MPa})$ & 1507 \\
\hline$\varepsilon_{f}^{\prime}$ & 0.027 \\
\hline Exponents & Value \\
\hline$b$ & -0.090 \\
\hline$c$ & -0.627 \\
\hline
\end{tabular}

Table 5.-Comparison of $V_{\sigma}$ at $N_{f}=1$ and $N / 2$ for Grainex Mar-M 247 at $649^{\circ} \mathrm{C}, R=0$.

\begin{tabular}{|c|c|c|c|c|}
\hline \multirow{2}{*}{$\begin{array}{c}\text { strain } \\
\text { range }\end{array}$} & at $\boldsymbol{N}=\mathbf{1}$ & \multicolumn{2}{|c|}{ at $\boldsymbol{N}_{\boldsymbol{f}} / \mathbf{2}$} & at $\boldsymbol{N}_{\boldsymbol{f}} / \mathbf{2}$ \\
\cline { 2 - 5 } & $\boldsymbol{V}_{\boldsymbol{\sigma}}$ & $\boldsymbol{\sigma}_{\boldsymbol{m}}[\mathbf{M P a}]$ & $\boldsymbol{\sigma}_{\mathbf{a}}[\mathbf{M P a}]$ & $\boldsymbol{V}_{\boldsymbol{\sigma}}$ \\
\hline 0.50 & 1 & 344.1 & 463.3 & 0.74 \\
\hline 0.50 & 1 & 281.0 & 472.7 & 0.59 \\
\hline 0.58 & 1 & 295.1 & 513.7 & 0.57 \\
\hline 0.58 & 1 & 247.9 & 562.3 & 0.44 \\
\hline 0.58 & 1 & 265.8 & 556.1 & 0.48 \\
\hline 0.67 & 1 & 227.5 & 598.5 & 0.38 \\
\hline 0.67 & 1 & 206.9 & 600.6 & 0.34 \\
\hline 0.67 & 1 & 180.6 & 608.1 & 0.30 \\
\hline 0.78 & 1 & 100.3 & 745.0 & 0.13 \\
\hline 0.78 & 1 & 153.8 & 669.5 & 0.23 \\
\hline 0.78 & 1 & 106.9 & 706.7 & 0.15 \\
\hline 0.90 & 1 & 88.6 & 734.7 & 0.12 \\
\hline 0.90 & 1 & 60.0 & 781.2 & 0.08 \\
\hline
\end{tabular}

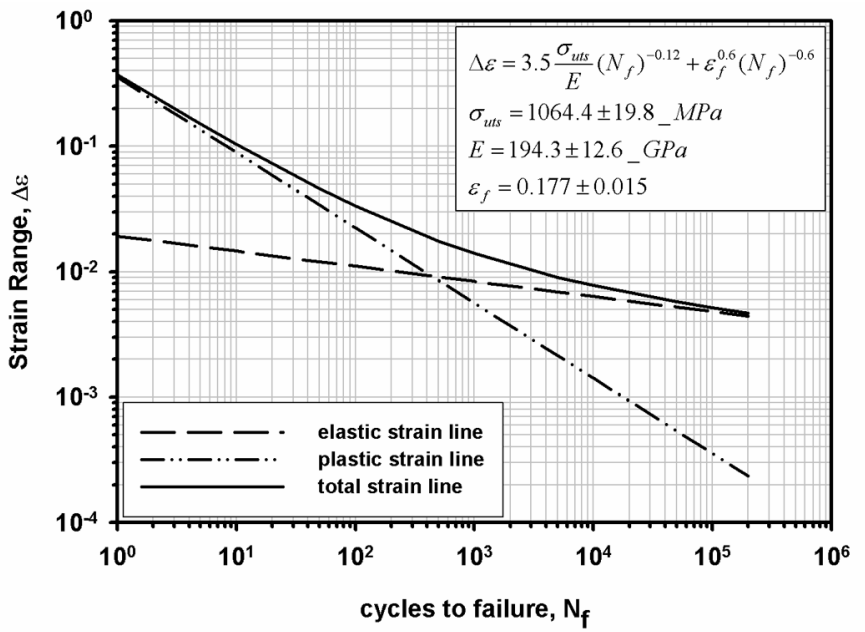

Figure 5.-Strain-life prediction using the Method of Universal Slopes equation and Grainex Mar-M 247 tensile data at $649^{\circ} \mathrm{C}$.

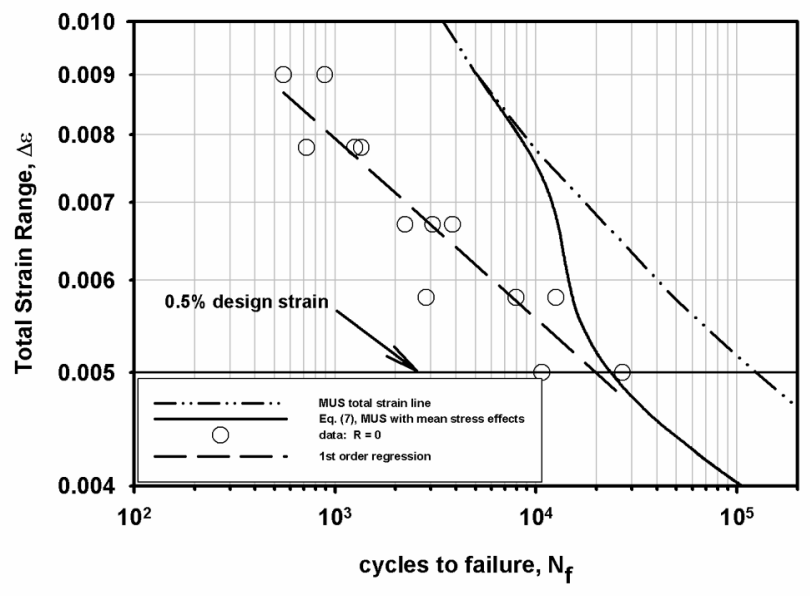

Figure 6.-Comparison of MUS, MUS with mean stress effects, and data for Grainex Mar-M 247 at $649^{\circ} \mathrm{C}$.

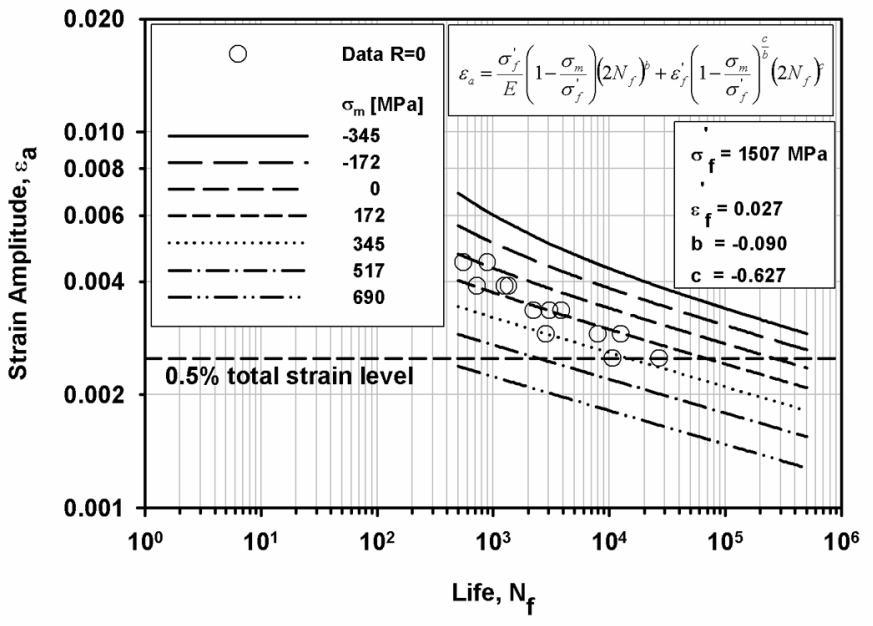

Figure 7.-Comparison of NASA Grainex Mar-M 247 $\boldsymbol{R}=\mathbf{0}$ data with the Modified Morrow equation at $649^{\circ} \mathrm{C}$. 


\section{Fractographic Examination}

The majority of the crack initiation sites were observed at the gage cross-section perimeter and initiated at carbides. As expected, the fracture surfaces exhibited 3 areas or stages of cracking - crack initiation, propagation, and failure or overload (figure 9).

\section{DISCUSSION: TENSILE BEHAVIOR}

The NASA Grainex Mar-M 247 tensile properties were within 5 to $10 \%$ of values reported in the literature data (table 6) $[10,11]$. The exception was in the $\% R A$ data where the NASA values were 30 to $40 \%$ higher than that reported in the literature. The higher values were most likely due to a slight amount of necking observed in the gage sections of the tensile test specimens.

Table 6.-Comparison of average Grainex Mar-M 247 tensile properties at $649^{\circ} \mathrm{C}$ with literature.

\begin{tabular}{|l|c|c|c|}
\hline & NASA $^{*}$ & Kaufman $^{*}[\mathbf{1 0}]$ & Howmet [11] \\
\hline No. Samples & 4 & 2 & N/A \\
\hline$E[\mathrm{GPa}]$ & 194.3 & N/A & 179.3 \\
\hline$\sigma_{\text {UTS }}[\mathrm{MPa}]$ & 1064.4 & 1011.5 & 1027.3 \\
\hline$\sigma_{y(0.2 \%)}[\mathrm{MPa}]$ & 821.0 & 799.1 & 827.4 \\
\hline$\% R A$ & 16 & 9.7 & 10.7 \\
\hline$\% E L$ & 6.9 & 7.1 & 7.0 \\
\hline * average data
\end{tabular}

\section{DISCUSSION: FATIGUE STRAIN-LIFE}

$\boldsymbol{R}=\mathbf{0}$

Testing at $R=0$ and $649{ }^{\circ} \mathrm{C}$ addressed the actual localized conditions the Grainex Mar-M 247 disk bolt holes encounter in the Turbine Seal Test Facility. Specifically, the disk is strained from a zero to maximum strain when the surface speed increases from zero to maximum during testing. The $-99.95 \%$ prediction interval (1 failure in 2000 samples) on cyclic life was chosen since it was more conservative than the mean cyclic life by a factor of approximately 10 . As expected, more data scatter was observed at the lower strain ranges. Overall the cyclic life to crack initiation of the bolt holes of the Grainex Mar-M 247 disk at the $0.5 \%$ design strain with $R=0$ and the lower bound of the $99.95 \%$ prediction interval was found to be 1100 cycles. This was nearly 6 times less than the cyclic life predicted from previous analyses [1].

\section{Comparison to Literature}

Comparison of the NASA Grainex Mar-M $247 R=0$ strain-life data with data reported by Kaufman showed good agreement (figure 10) [10]. The NASA data at $649{ }^{\circ} \mathrm{C}$ fell in between the $427{ }^{\circ} \mathrm{C}$ and $760{ }^{\circ} \mathrm{C}$ data reported by Kaufman [10]. As expected, cyclic lives decreased with increasing temperature for a constant strain range.

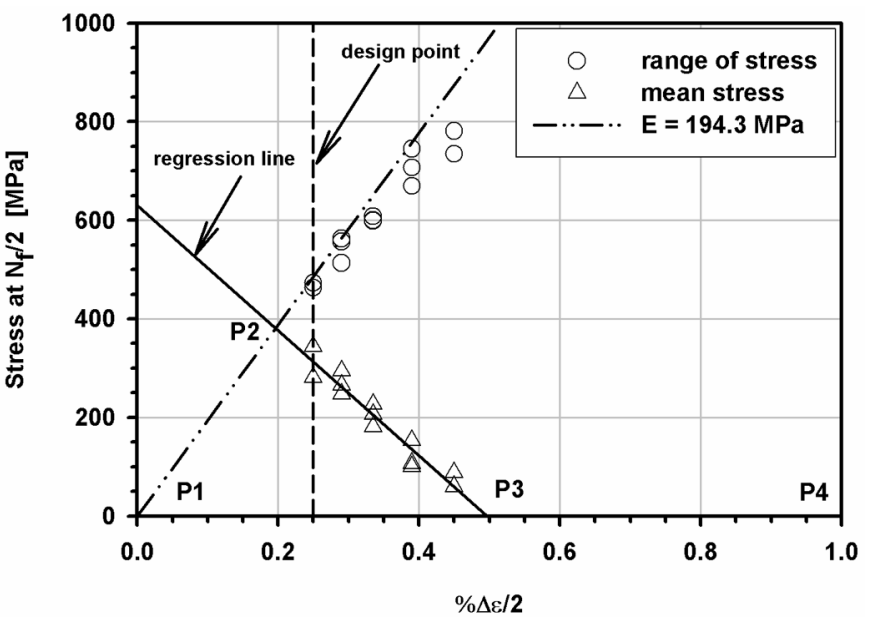

Figure 8.-Variation of mean stress and range of stress with strain amplitude at $N / 2$ for Grainex Mar-M 247 at $649^{\circ} \mathrm{C}$. [9]

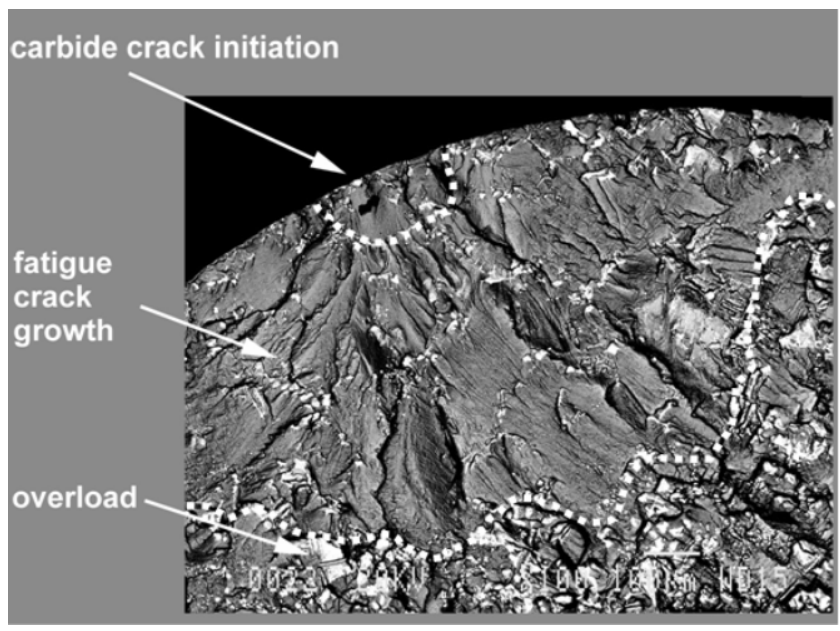

Figure 9.-Typical fatigue crack growth stages for Grainex Mar-M 247 strain-life specimen at $649^{\circ} \mathrm{C}$. SEM - BE mode at $100 \mathrm{x}$.

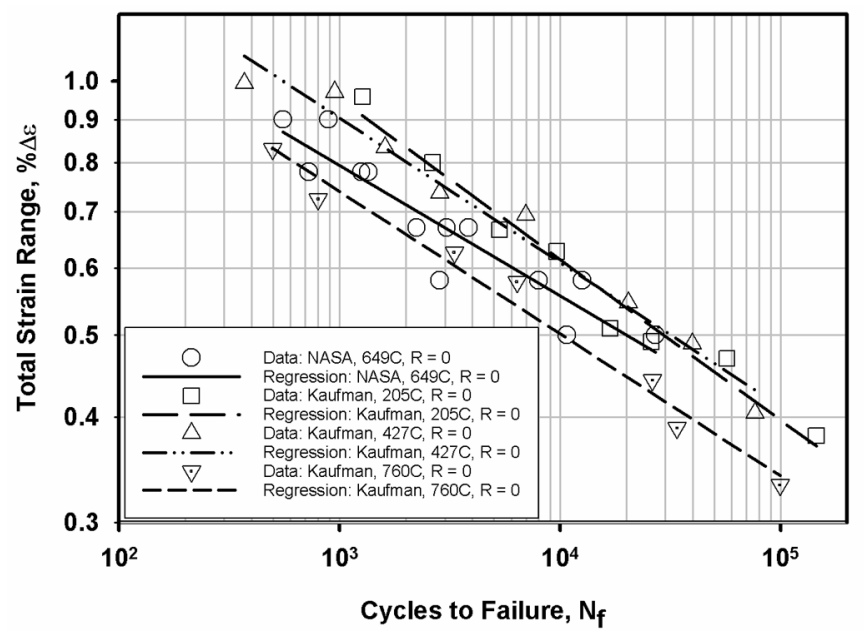

Figure 10.-Comparison of NASA Grainex Mar-M 247, $R=0$ strain-life data with literature. [10] 


\section{Comparison with MUS, Mean Stress Effects and Data}

Both the MUS and eq. (7) provide a means to predict fatigue strain-life by use of only tensile data. It was expected that the MUS would over-predict the $R=0$ data (figure 6) since it was generally used in comparing $R=-1$ data. At the design point of $0.5 \%$ total strain, the MUS predicted $N_{f 0}$ at 100,000 cycles. This is 5 times greater than the average $R=0$ data of approximately 20,000 cycles. In comparison, eq. (7) predicted a life of approximately 23,500 cycles (figure 6). Thus, a more accurate prediction of life at the $0.5 \%$ total strain design point was found using only tensile data and modifying the MUS to account for mean stress effects.

\section{Comparison to Modified Morrow Equation}

Parametric curves of constant mean stress were compared to the experimental results on a strain-amplitude versus cycles to failure plot using results of the Modified Morrow strain-life analysis (figure 7). As expected, higher mean stresses were observed at lower strain levels while lower mean stresses were observed at higher strain levels (figure 8) [9]. This is because the larger the strain range, the greater the degree of relaxation of the initial mean stress imposed by the $R=0$ strain condition. The effect of mean stress on cyclic life was more pronounced at lower strain levels (table 5). For example, at the design strain level of $0.5 \%$ total strain, the average mean stress was $313 \mathrm{MPa}$, while at $0.9 \%$ total strain, the average mean stress was $74 \mathrm{MPa}$.

As expected, cyclic life decreased as mean stress increased for constant strain amplitude (figure 7). For example at the design point of $\Delta \varepsilon=0.5 \%\left(\varepsilon_{a}=0.0025\right)$ the difference in cyclic life between the $\sigma_{m}=0 \mathrm{MPa}$ line and the $\sigma_{m}=172 \mathrm{MPa}$ line was nearly a factor of four. The $R=0$ data were observed to trend towards a zero mean stress at the highest strain range $\left(\varepsilon_{a}=0.0045\right)$. Finally, as expected, compressive mean stresses predict an increase in cyclic life.

\section{SUMMARY}

Tensile properties for the Grainex Mar-M 247 disk at $649{ }^{\circ} \mathrm{C}$ were presented and compared with literature data. Fatigue strain life data for the same material were also presented at $649{ }^{\circ} \mathrm{C}$ at strain ranges of $0.50 \%, 0.58 \%, 0.67 \%$, $0.78 \%$, and $0.90 \%$. Both the tensile and $R=0$ strain-life data were comparable with literature.

Evaluation of mean stress effects showed a large effect on cyclic life. The Halford-Nachtigall Method used with the MUS was practical for predicting $R=0$ life using only tensile data at $649{ }^{\circ} \mathrm{C}$. A difference of only $18 \%$ in cyclic life was observed between predicted and experimental lives at the design point of $0.5 \%$ strain range. The 10,000 cycle limit suggested by the Modified Morrow analysis at the $0.5 \%$ design strain range can be reduced accordingly to 1500 cycles using an equivalent $-3 \sigma$ reduction factor and probabilistic accounting for the 6 bolt holes using eq. (1).

During operation the turbine disk is generally cycled at zero to maximum strain conditions $(R=0)$. At the design strain of $\Delta \varepsilon=0.5 \%$ the $R=0$ results lead to, at the $-99.95 \%$ prediction level, a cyclic crack initiation life of 1100 cycles which is nearly 6 times less than the initial predicted cycles to failure obtained previously by Tong and Steinetz [1]. Probabilistic accounting for the 6 bolt holes using eq. (1) gives the most conservative result of 665 cycles with 6 bolt holes.

Thus, using the experimental data at a $-99.95 \%$ prediction level and the presence of 6 bolt holes it was found that the disk should be inspected for surface cracks after 665 cycles based on a total strain range of $0.50 \%$ at $649{ }^{\circ} \mathrm{C}$.

\section{REFERENCES}

[1] Tong, M., and Steinetz, B., 1997, "Grainex Mar-M 247 Disk FEA Thermal and Stress Analysis," NASA High Speed Seal Test Rig Engineering Manual, NASA Glenn Research Center, Cleveland, Chapter 7.

[2] Melis, M.E., Zaretsky, E.V., and August, R., 1999, "Probabilistic Analysis of Aircraft Gas Turbine Disk Life and Reliability," AIAA Journal of Propulsion and Power, 15, pp. 658-666.

[3] Lundberg, G., and Palmgren, A., 1947, "Dynamic Capacity of Rolling Bearings," Acta Polytechnica, Mechanical Engineering Series, 1, pp. 1-49.

[4] Keller, D.J., 1992, Introduction to Regression, RealWorld Quality Systems, Inc., Fairview Park.

[5] Manson, S.S., 1965, "Fatigue-A Complex Subject," Experimental Mechanics, 5, pp.193-226.

[6] Halford, G.R., and Nachtigall, A.J., 1980, "Strainrange Partitioning Behavior of an Advanced Gas Turbine Disk Alloy AF2-1DA," Journal of Aircraft, 17, pp. 598-604.

[7] Dowling, N.E., 1999, Mechanical Behavior of Materials: engineering methods for deformation, fracture and fatigue, Prentice-Hall, Inc., Upper Saddle River.

[8] Morrow, J., 1968, Fatigue Design Handbook, SAE, New York.

[9] Conway, J.B., and Sjodahl, L.H., 1991, Analysis and Representation of Fatigue Data, ASM International, Materials Park.

[10] Kaufman, M., 1984, "Properties of Cast Mar-M 247 for Turbine Blisk Applications," Superalloys 1984, M. Gell et al., eds., Metallurgical Society of AIME, Warrendale, pp. 43-52.

[11] Howmet Turbine Components Corporation, "TB 3000: Grainex Cast Mar-M 247 Alloy," Howmet Turbine Components Corporation, Greenwich. 


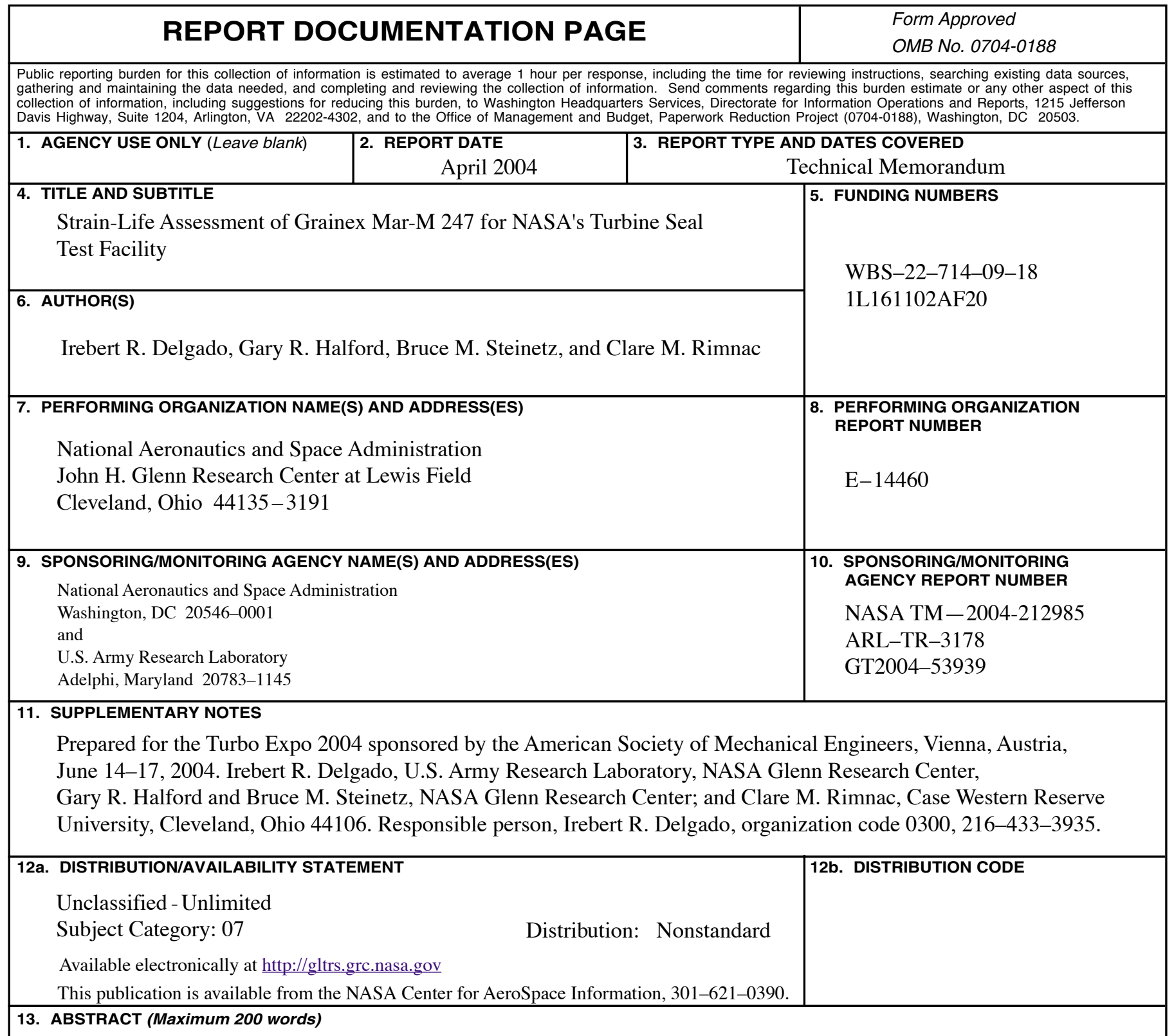

NASA's Turbine Seal Test Facility is used to test air-to-air seals for use primarily in advanced jet engine applications.

Combinations of high temperature, high speed, and high pressure limit the disk life, due to the concern of crack initiation in the bolt holes of the Grainex Mar-M 247 disk. The primary purpose of this current work is to determine an inspection interval to ensure safe operation. The current work presents high temperature fatigue strain-life data for test specimens cut from an actual Grainex Mar-M 247 disk. Several different strain-life models were compared to the experimental data including the Manson-Hirschberg Method of Universal Slopes, the Halford-Nachtigall Mean Stress Method, and the Modified Morrow Method. The Halford-Nachtigall Method resulted in only an 18 percent difference between predicted and experimental results. Using the experimental data at a -99.95 percent prediction level and the presence of 6 bolt holes it was found that the disk should be inspected after 665 cycles based on a total strain of 0.5 percent at $649{ }^{\circ} \mathrm{C}$.

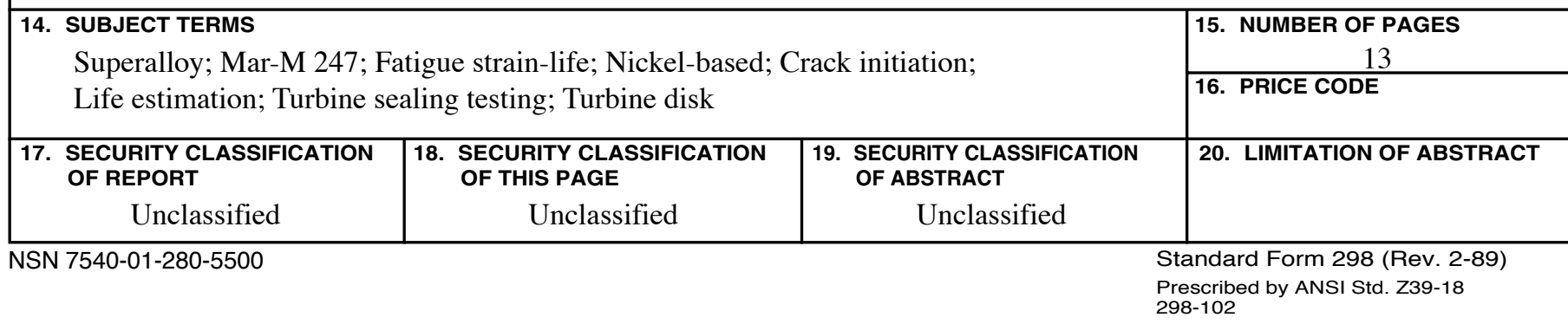



